\title{
Evaluation of Topical Gel Bases Formulated with Various Essential Oils for Antibacterial Activity against Methicillin- Resistant Staphylococcus Aureus
}

\author{
Marwa H Shukr ${ }^{1^{*}}$ and Ghada F Metwally ${ }^{2}$ \\ ${ }^{1}$ Department of Pharmaceutics, and ${ }^{2}$ Department of Plant Tissue Culture, National Organization for Drug Control and Research \\ (NODCAR), Cairo, Egypt \\ *For correspondence: Email: marwa_25_2001@hotmail.com
}

\begin{abstract}
Purpose: To formulate topical gels containing various essential oils and evaluate their antibacterial activity against methicillin-resistant Staphylococcus Aureus (MRSA) skin infections.

Methods: The four essential oils namely, lemon grass, rosemary, thyme and basil were steam-distilled and then evaluated for their antibacterial activity against MRSA. Lemon grass and thyme oils were chosen for further studies, including analysis of their composition by gas chromatography-mass spectrometry (GC/MS). Gels were formulated using carbopol 940, hydroxypropylmethyl cellulose, sodium carboxymethy cellulose with lemon grass oil and evaluated for their physical appearance, $\mathrm{pH}$, spreadability rheological properties, antibacterial activity against MRSA and skin irritation in human volunteers. The selected gels were prepared with thyme oil alone or in combination with lemon grass oil and compared with that containing lemon grass oil alone.

Results: The minimum inhibitory concentration (MIC) of lemon grass and thyme oils were 30 and 4 $\mu \mathrm{l} / \mathrm{ml}$, respectively. Carbopol 940 gel (0.75\%) containing lemon grass oil showed good physical characteristics, including spreadability and rheological properties; it also showed the strongest antibacterial activity of the gels tested. No significant difference $(p \leq 0.05)$, were observed between the characteristics of the gels containing thyme oil alone and in combination with lemon grass oil. The antibacterial activity of the gel containing the two oils was approximately the sum of those containing the individual oils. No signs or symptoms of lesions, redness or itching were found when the gels were applied to the skin.

Conclusion: The carbopol $940 \mathrm{gel}$ containing lemon grass and thyme oils possess good antibacterial activity against MRSA when applied to human skin, and exhibit no skin irritation.
\end{abstract}

Keywords: Essential oil, Methicillin-resistant Staphylococcus aureus, Topical gel, Antibacterial, Spreadability, Rheology, Skin irritation

Tropical Journal of Pharmaceutical Research is indexed by Science Citation Index (SciSearch), Scopus, International Pharmaceutical Abstract, Chemical Abstracts, Embase, Index Copernicus, EBSCO, African Index Medicus, JournalSeek, Journal Citation Reports/Science Edition, Directory of Open Access Journals (DOAJ), African Journal Online, Bioline International, Open-J-Gate and Pharmacy Abstracts

\section{INTRODUCTION}

Topical antimicrobial therapy is the most important aspect of wound care for the prevention of infections [1]. Despite the development of antibiotics, bacterial and fungal infections still constitute a major issue in medicine. Due to the presence and increase of numerous drug-resistant strains, an urgent need exists to develop novel antimicrobial agents [2]. Staphylococcus aureus is a common pathogen causing infections that range from minor skin lesions to life threatening conditions. Methicilin- 
resistant Staphylococcus aureus (MRSA) appeared in the 1990s and became a huge problem worldwide as a result of their resistance to antibiotics. It is probably one of the most common antibiotic-resistant bacteria that has caused alarm in the healthcare system. It naturally colonises the skin and infects wounds [3]. Alternative therapies are required for the treatment of MRSA and one area of interest is the use of essential oils. In the last decade, there has been an increased interest in essential oils and their activity against MRSA. There were also several clinical studies regarding the successful use of essential oils in treating MRSA infections [4].

Therefore, the aim of the present study was to investigate the antibacterial activity of topical gels formulated with various essential oils against MRSA.

\section{EXPERIMENTAL}

\section{Plant materials}

The plants used in this study include the nonflowering aerial parts of Thymus vulgaris (Thyme), Ocimum basilicum (Basil), Cymbopogan citratus (Lemon grass) and Rosmarinus officinalis (Rosemary), and were collected in November and December 2011. Thyme and basil plants were obtained from the Experimental Station Center of Medicinal Plants, Pharmacognosy Department, Faculty of Pharmacy, Giza, Egypt. Lemon grass and rosemary plants were obtained from the Applied Research Center, National Organization for Drug Control and Research (NODCAR), Giza, Egypt. The plants were authenticated by Mrs. Therese Labib, Consultant of Orman Botanical Garden. Voucher samples of thyme (lam/Th.v/11-12/11), basil (lam/Ob/11-12/11), lemon grass (Poa/Cc/11-12/11) and rosemary (lam/Ro/1112/11) have been kept for future reference in the herbarium of the Plant Tissue Culture Department (NODCAR).

\section{Other materials}

Carbopol 940 (Cp940) from obtained from Bf. Goodrich, Co (USA). Propylene glycol (PG), hydroxypropyl methyl cellulose (HPMC, medium viscosity), and sodium carboxymethyl cellulose (Na CMC, medium viscosity) were supplied from Biochemica (Switzerland). Triethanolamine was obtained from Sigma (USA), while antibiotic discs (erythromycin, ofloxacin, doxacycline, clarithromycin and amikacin) were supplied from Oxoid company (USA).

\section{Bacterial isolates}

Clinical isolates of methicillin-resistant Staphylococcus aureus (MRSA) used in this study, were collected from different clinical microbiological laboratories in hospitals over a period of one year, through 2011.

\section{Extraction of essential oils}

The freshly collected non-flowering aerial parts of the four plants under study were, separately, chopped and hydrodistilled for $3 \mathrm{~h}$ using a Clevenger apparatus [5].

\section{Gas chromatography-mass spectroscopy (GC/MS) analysis}

GC/MS analysis was carried out using an Agilent 6890 gas chromatograph coupled with an Agilent 5973 mass spectrometric detector. A fused silica capillary column (HP-5MS), $5 \%$ phenylmethyl siloxane (30 m x $0.25 \mu \mathrm{m}$ film thickness) was used with helium as carrier gas at a flow rate 1.0 $\mathrm{ml} / \mathrm{min}$. A $1 \mu \mathrm{l}$ volume was injected in pulsed splitless mode. The temperature programming was performed as follows: the column temperature was maintained at $80^{\circ} \mathrm{C}$ for 2 min, then increased from $80{ }^{\circ} \mathrm{C}$ to $270{ }^{\circ} \mathrm{C}$ at 15 ${ }^{\circ} \mathrm{C} / \mathrm{min}$. and finally isothermal for $10 \mathrm{~min}$. The injector port temperature was $260{ }^{\circ} \mathrm{C}$. El/MS spectrum was recorded at $70 \mathrm{eV}$ (ion source temperature: $250{ }^{\circ} \mathrm{C}$ ). The mass range was 50 to $700 \mathrm{~m} / \mathrm{z}$. The essential oil components were identified by comparison of their mass spectra with the spectra stored in Wiley library as well as published mass spectra [6].

\section{Determination of antibacterial activity of essential oils}

Screening of the four essential oils for antibacterial activity against MRSA was done by agar well diffusion method [7] on solid agar (Oxoid) media. Each essential oil $(200 \mu \mathrm{l})$ was placed in each well and the agar plates incubated for $24 \mathrm{~h}$ at $37^{\circ} \mathrm{C}$. The zones of growth inhibition were recorded.

\section{Determination of minimal inhibitory concen- tration (MIC)}

Based on the previous screening, the MIC of the selected oils was determined. A series of dilution of each oil, ranging from 128 to $2 \mu \mathrm{l} / \mathrm{ml}$, was used; the plates were inoculated with the bacterial suspension and incubated for $24 \mathrm{~h}$ at $37{ }^{\circ} \mathrm{C}$. MIC was determined as the lowest concentration of the oil inhibiting visible growth of MRSA on the agar plate [7]. 


\section{Preparation of gel bases containing selected essential oils}

Different gels were prepared using different concentrations of Carbopol 940 (0.75 and $1 \%$ ), Na CMC (2 and 3\%) and HPMC (8 and $10 \%$ ) as gelling agents. The required amount of the polymer was dispersed in purified water in a beaker and stirred using a magnetic stirrer. Propylene glycol (10\% $\mathrm{w} / \mathrm{w})$ was added and stirred until a homogenous gel was achieved. For gels containing $\mathrm{Na} \mathrm{CMC}$, the polymer was dispersed in the purified water and kept in a refrigerator overnight. The essential oil that showed the highest zone of inhibition with moderate yield was added to the previous polymer dispersion with stirring. For Carbopol 940, adequate amount of triethanolamine was added to neutralize free carboxylic acid groups of carbopol 940 to $\mathrm{pH}$ $6.8 \pm 0.2[8]$.

\section{Evaluation of the gels}

The gels containing essential oil were examined for their physical properties. Rheological properties and antibacterial activity were also evaluated. Finally, the skin irritation test was carried out only on selected formulations.

\section{Visual inspection}

The gels were examined for their physical properties by visual inspection of color, clarity, homogeneity and phase separation.

\section{Determination of $\mathrm{pH}$}

The $\mathrm{pH}$ of the gels was measured using a digital $\mathrm{pH}$ meter (HANNA). The results are the mean of three readings.

\section{Spreadability}

Spreadability was determined using an apparatus [9] which was adapted in-house. It consists of a wooden block, which was provided by a pulley at one end. By this method, spreadability was measured on the basis of "slip" and "drag" characteristics of the gels. A ground glass slide was fixed on this block. An excess of gel (about 2 g) under study was placed on this ground slide. The gel was then sandwiched between this slide and another glass slide having the dimension of fixed ground slide and provided with a hook. A weight of $100 \mathrm{~g}$ was placed on the top of the two slides for $5 \mathrm{~min}$ to expel air and to provide a uniform film of the gel between the slides. Excess of the gel was scrapped off from the edges. The top plate was then subjected to a pull of $20 \mathrm{~g}$ weight with the help of a string attached to the hook and the time (in seconds) required by the top slide to cover a distance of $7.5 \mathrm{~cm}$ was noted. A shorter interval indicates better spreadability [10]. Spreadability (S) was calculated as in Eq 1.

$S=M \cdot L / t$

where $M$ is the weight $(\mathrm{g})$ tied to the upper glass slide $L$ is the length $(\mathrm{cm})$ moved on the glass slide, and $t$ is time (sec).

Determinations were made in triplicates.

\section{Assessment of rheological properties}

The rheological properties of the gels were evaluated using a rotational Brookfield viscometer of cone and plate structure (model DV III, USA). About $0.5 \mathrm{~g}$ of the gel was applied to the plate and left until the temperature of the cone $\left(25 \pm 1{ }^{\circ} \mathrm{C}\right)$ was reached. Readings were taken over a large range of shearing rates (from 0.75 to $1875 \mathrm{~s}^{-1}$ ) corresponding to 0.1 to 250 rpm. Viscosity and degree of pseudoplasticity (Farrow's constant) were determined. To study the flow behavior of the gels, Farrow's equation was applied as in Eq 2 [11]:

$\log G=N \log F-\log \eta$

where: $\mathrm{G}$ is shear rate $\left(\mathrm{sec}^{-1}\right), \mathrm{N}$ is Farrow's constant, $F$ is shear stress (dyne/ $\mathrm{cm}^{2}$ ) and $\eta$ is viscosity (c.p.).

Log $G$ was plotted against Log $F$ to obtain the value of $\mathrm{N}$, which indicates deviation from Newtonian flow.

\section{Determination of antibacterial activity of the gels}

The prepared gels were evaluated for their antibacterial activity against MRSA by agar well diffusion method [7]. The susceptibility of MRSA against five commonly used antibiotics was tested [12]. The discs of antibacterial agents used as reference standards were erythromycin (EM) $15 \mu \mathrm{g} /$ disc, ofloxacin (OFX) $5 \mu \mathrm{g} /$ disc, doxacycline (DOX) $30 \mu \mathrm{g} /$ disc, clarithromycin (CLR) $15 \mu \mathrm{g} /$ disc and amikacin (AK) $30 \mu \mathrm{g} /$ disc. The diameter of the inhibition zones were measured in $\mathrm{mm}$.

\section{Skin irritation test}

Skin irritation test was performed for the selected gels on human volunteers to find out any irritation problems which could make it unsuitable for topical use. Skin irritation test was performed, for each gel on three volunteers. Approximately $1 \mathrm{~g}$ gel was topically applied to the hand near the wrist over a 2 square inch 
area and observed for any lesions or irritation/redness [13].

\section{Statistical analysis}

The results were statistically analyzed by an unpaired two-tailed t-test ( $p \leq 0.05)$, using Instat software version 3.05 (GraphPad, San Diego, CA, USA), to determine whether the results were significantly different or not.

\section{RESULTS}

\section{Antibacterial activity of the essential oils against MRSA}

The four essential oils showed varying antibacterial effect on MRSA (Table 1). Thyme and basil oils showed the highest inhibitory effect against MRSA. Moderate effect was exerted by lemon grass oil while the least activity was produced by rosemary oil. No significant difference $(p \leq 0.05)$ was observed between the antibacterial activities of thyme and basil oils. Lemon grass and thyme oils were chosen for further investigation due to their higher yields. The MIC of lemon grass and thyme essential oils were $30 \mu \mathrm{l} / \mathrm{ml}$ and $4 \mu \mathrm{l} / \mathrm{ml}$, respectively.

Table 1: Yield and antibacterial activity (zone of inhibition) of the essential oils

\begin{tabular}{lll}
\hline Essential oil & $\begin{array}{l}\text { Yield } \\
(\%)\end{array}$ & $\begin{array}{l}\text { Zone of inhibition } \\
\text { (mm } \pm \mathbf{s d})\end{array}$ \\
\hline Lemon grass oil & 1.23 & $30.5 \pm 0.50$ \\
Rosemary oil & 0.20 & $20.26 \pm 0.25$ \\
Thyme oil & 0.32 & $40.1 \pm 0.15$ \\
Basil oil & 0.02 & $39.7 \pm 0.30$ \\
\hline
\end{tabular}

\section{Chemical composition of essential oils}

Twenty components were identified in lemon grass oil by GC/MS, which represented $87.57 \%$ of the oil, while fifteen components were identified in thyme oil which represented $92.31 \%$ of the oil.

The components identified in lemon grass oil were: five monoterpenes (19.22 \%), four sesquiterpenes $(1.2 \%)$, five alcohols $(1.65 \%)$ two aldehydes $(34.87 \%)$, one ketone $(1.45 \%)$, one ester $(26.87 \%)$ and two miscellaneous compounds $(2.31 \%)$. On the other hand, thyme oil contained one monoterpene (34.59\%), four sesquiterpenes $(20.68 \%)$, seven alcohols $(31.75$ $\%)$, one ketone $(0.26 \%)$, one ester $(2.46 \%)$ and one miscellaneous compound (2.57 \%).

The four chosen hydrodistilled plants afforded yield of essential oils and antibacterial activity (mean $\pm S D, n=3$ ) listed in Table 2 .

Table 2: Composition of gels

\begin{tabular}{cccccc}
\hline $\begin{array}{c}\text { Formula } \\
\text { code }\end{array}$ & $\begin{array}{c}\text { Cp940 } \\
(\%)\end{array}$ & $\begin{array}{c}\text { HPMC } \\
(\%)\end{array}$ & $\begin{array}{c}\text { Na } \\
\text { CMC } \\
(\%)\end{array}$ & $\begin{array}{c}\text { PG } \\
(\%)\end{array}$ & $\begin{array}{c}\text { Lemon } \\
\text { grass oil } \\
(\%)\end{array}$ \\
\hline F1 & 0.75 & -- & -- & 10 & 3 \\
F2 & 1 & -- & -- & 10 & 3 \\
F3 & - & 8 & -- & 10 & 3 \\
F4 & - & 10 & - & 10 & 3 \\
F5 & - & -- & 2 & 10 & 3 \\
F6 & - & --- & 3 & 10 & 3 \\
\hline
\end{tabular}

Water was added to make up to $100 \mathrm{~g}$ of each gel

\section{Gel characteristics}

The composition of the prepared gels is given in table (2). The gels were prepared first with lemon grass oil as it showed higher yield than thyme oil. All the gels were homogenous, slightly turbid with characteristic odor of the essential oil. Table 3 shows the $\mathrm{pH}$ values and spreadability of the prepared gels. All the gels showed $\mathrm{pH}$ values in the range of $6.1 \pm 0.7$, except for gels containing $\mathrm{Na}$ CMC, which were in the range of $7.8 \pm 0.2$. Spreadability was in the range of 8.4 to 15 $\mathrm{gm} . \mathrm{cm} / \mathrm{sec}$. Maximum spreadability was observed for gels containing $\mathrm{Na}$ CMC (2 and 3 $\%)$, followed by that containing HPMC (10\%), and then that formulated with $0.75 \%$ Carbopol 940.

\section{Rheological properties of gels}

Table 3 and Figure 1 show the rheological characteristics of the gels. Carbopol 940 gels

Table 3: Physicochemical characteristics of the gels

\begin{tabular}{lcccccc}
\hline $\begin{array}{l}\text { Gel } \\
\text { Code }\end{array}$ & $\begin{array}{c}\text { pH } \\
\text { (mean } \mathbf{m} \\
\mathbf{S D}, \mathbf{n}=\mathbf{3})\end{array}$ & $\begin{array}{c}\text { Spreadability } \\
\text { (mean } \mathbf{S} \text { SD, } \\
\mathbf{n = 3 )}\end{array}$ & $\begin{array}{c}\text { Viscosity } \\
\text { at minimum } \\
\text { shear rate } \\
\text { (cp) }\end{array}$ & $\begin{array}{c}\text { Viscosity at } \\
\text { maximum } \\
\text { shear rate } \\
\text { (cp) }\end{array}$ & $\begin{array}{c}\text { Farrow's } \\
\text { constant }\end{array}$ & $\begin{array}{c}\text { Zone of } \\
\text { inhibition } \\
\text { (mm, mean } \pm \\
\text { SD, } \mathbf{n = 3} \text { ) }\end{array}$ \\
\hline F1 & $6.6 \pm 0.0$ & $11.0 \pm 0.5$ & 230350 & 3264 & 5.4 & $24.0 \pm 0.2$ \\
F2 & $6.7 \pm 0.1$ & $8.5 \pm 0.3$ & 250480 & 3321 & 5.8 & $21.0 \pm 0.3$ \\
F3 & $5.5 \pm 0.1$ & $8.4 \pm 0.3$ & 1046 & 76 & 1.12 & $24.0 \pm 0.2$ \\
F4 & $5.9 \pm 0.1$ & $11.2 \pm 0.5$ & 1342 & 114 & 1.3 & $21.8 \pm 0.2$ \\
F5 & $7.7 \pm 0.1$ & $12.8 \pm 0.6$ & 1469 & 406 & 1.31 & $23.0 \pm 0.2$ \\
F6 & $8.0 \pm 0.1$ & $15.0 \pm 0.8$ & 1864 & 621 & 1.4 & $22.9 \pm 0.1$ \\
\hline
\end{tabular}




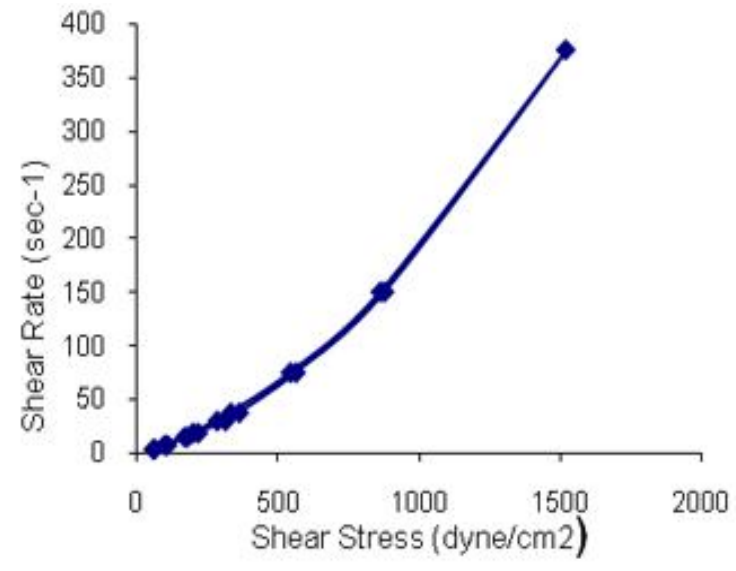

(a)

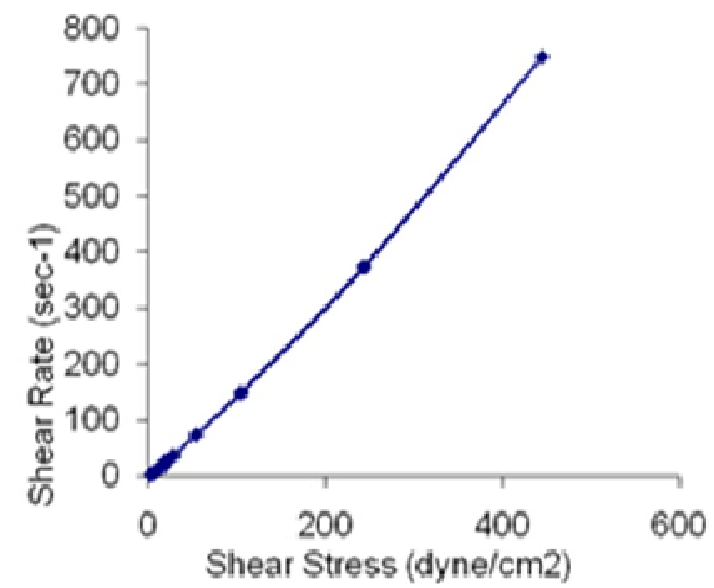

(c)

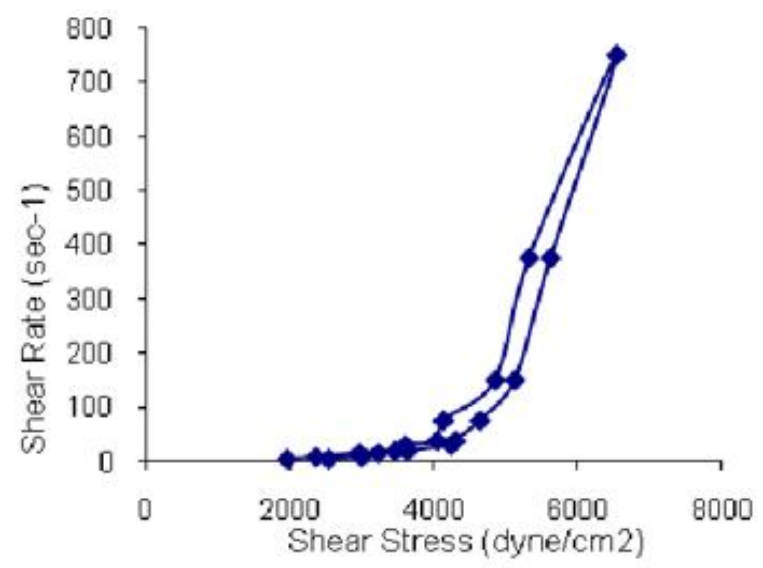

(e)

(b)
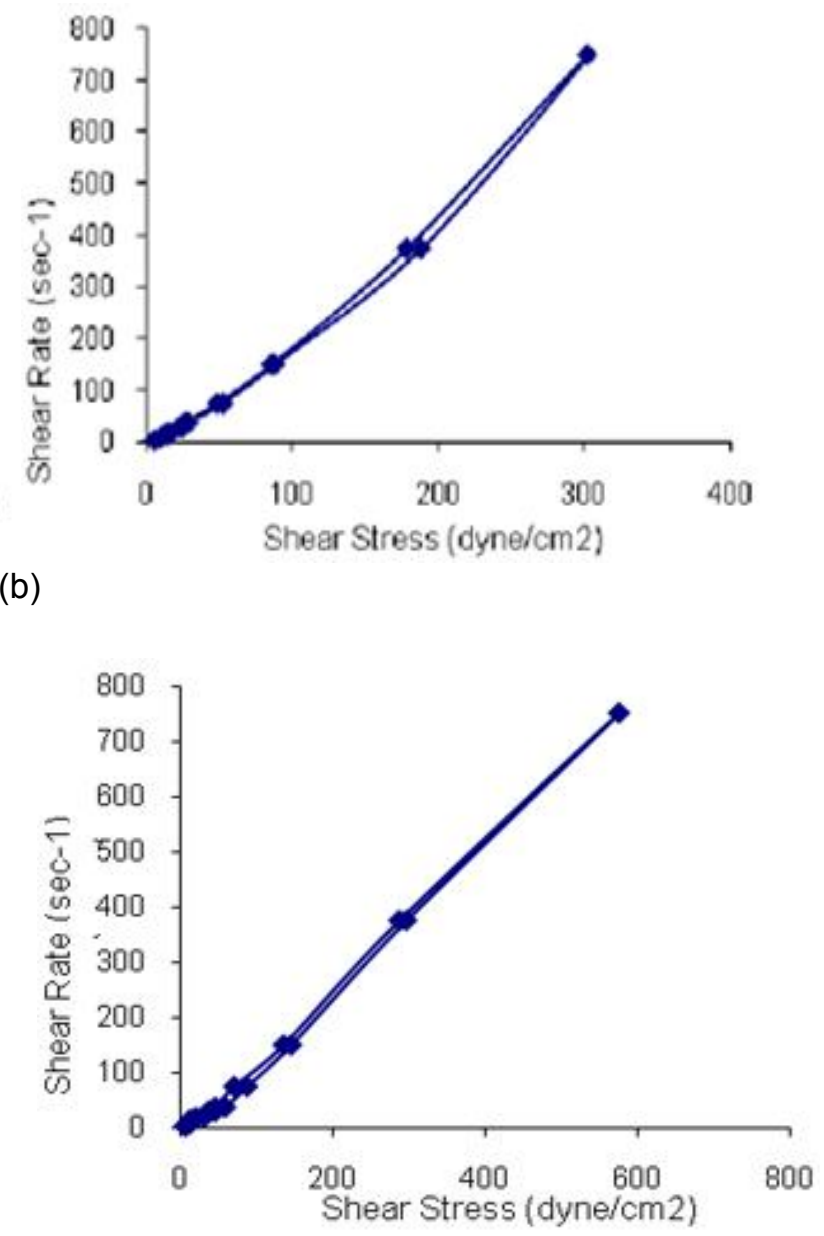

(d)

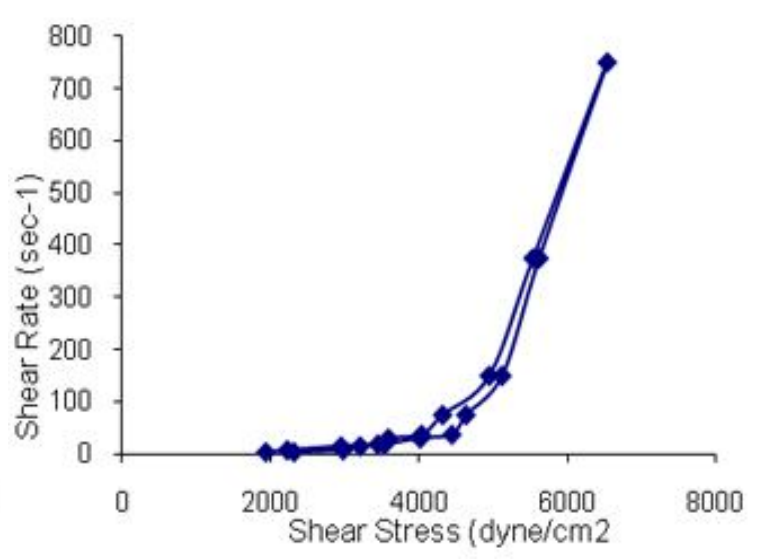

(f)

Fig 1: Rheogram of prepared lemon grass oil gels containing (a) $2 \% \mathrm{NaCMC}$, (b) $3 \% \mathrm{NaCMC}$, (c) $8 \% \mathrm{HPMC}$, (d) $10 \%$ HPMC, (e) $0.75 \%$ Carbopol 940, and (f) $1 \%$ Carbopol 940

showed the highest viscosity at minimum and maximum rates of shear. All the tested gels showed pesudoplastic flow with variable thixotropic behavior. The highest Farrow's constant was 5.8 and 5.4 for 1 and $0.75 \%$ Carbopol 940 gel, respectively.

\section{Antibacterial activity of the prepared gels}

The antibacterial activities of the prepared gels containing lemon grass were tested against MRSA via the agar well diffusion method and compared with the results of the tested antibiotics. According to the National Committee for Clinical Laboratory Standards (NCCLS) 
MRSA were sensitive to the tested antibiotics except erythromycin. All essential oil gel formulations showed higher antibacterial activity against MRSA than tested antibiotic discs (EM, DOX, CLR and AK) with a zone of inhibition of $20 \mathrm{~mm}$ except that containing ofloxacin (OFX) which showed a zone of inhibition of $25 \mathrm{~mm}$. There was no significant difference $(p \leq 0.05)$ between zones of $\mathrm{F} 1$ and $\mathrm{F} 3$ formulations and ofloxacin (OFX).

Based on the foregoing results, the gel containing $0.75 \%$ Carbopol 940 with $3 \%$ grass oil (F1) was selected and prepared with $0.4 \%$ thyme oil alone (F7) or in combination with lemon grass oil (F8). Table 4 and Figure 2 show the physicochemical and rheological characteristics of the resulting gels. No significant change in physical appearance, $\mathrm{pH}$, spreadability, rheological characteristics between the three gel formulations.

However, while the antibacterial activity of the gels containing only thyme oil was significantly higher $(p \leq 0.05)$ than that containing only lemon grass, the antibacterial activity of the gel containing both oils was approximately the sum of that of the gels containing the individual oils.

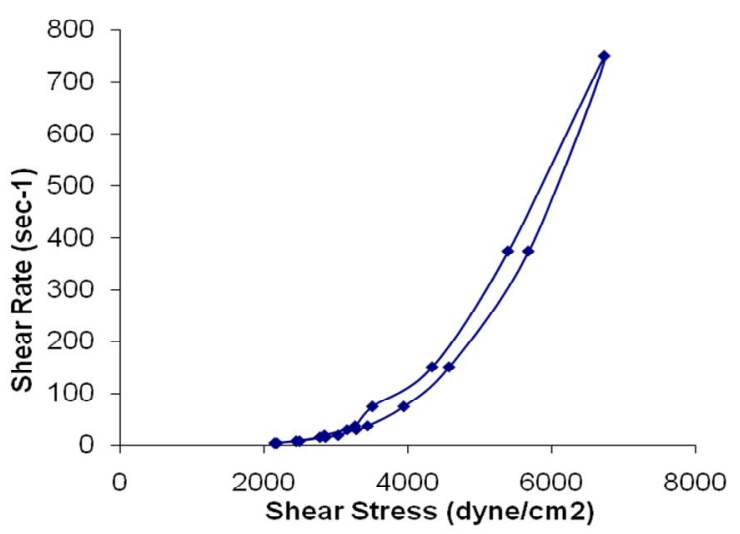

(a)
On applying the gel to the skin of human volunteers, no signs or symptoms of lesions, redness or itching were found.

\section{DISCUSSION}

Plant essential oils have been used for thousands of years in food preservation, pharmaceuticals, alternative medicine and natural therapies. They are potential sources of novel antimicrobial compounds especially against bacterial pathogens [14]. An important characteristic of essential oils and their components is their hydrophobicity, that enables them to partition into lipids of the bacterial cell membrane, thus disturbing the cell structure and rendering it more permeable, leading to cell death.

In vitro studies in this work showed that the essential oils under investigation (lemon grass, rosemary, thyme and basil oils) inhibited the growth of MRSA but their effectiveness varied. A previous study [4] also reported the inhibitory activities of these oils against MRSA.

Thyme and basil oils exhibited strong activity against MRSA, while lemon grass oil showed

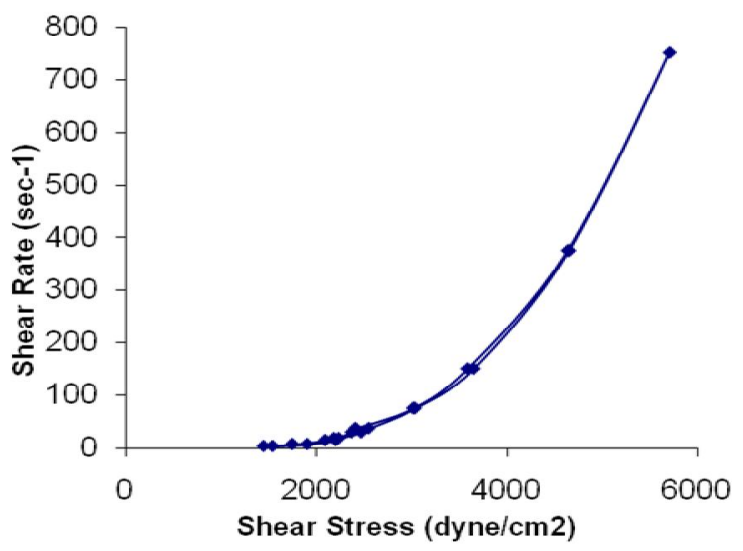

(b)

Figure 2: Rheogram of Carbopol 940 gels containing (a) thyme oil alone and (b) thyme oil with lemon grass oil

Table 4: Physicochemical characteristics of selected gel formulations

\begin{tabular}{llll}
\hline Parameter & F1 & F7 & F8 \\
\hline $\mathrm{pH}($ mean $\pm \mathrm{S} . \mathrm{D}, \mathrm{n}=3)$ & $6.61 \pm 0.05$ & $6.67 \pm 0.10$ & $6.56 \pm 0.10$ \\
Spreadability ( mean $\pm \mathrm{SD}, \mathrm{n}=3)$ & $10.96 \pm 0.46$ & $9.79 \pm 0.36$ & $9.58 \pm 0.36$ \\
$\mathrm{n}$ at minimum shear rate $(\mathrm{cp})$ & 230350 & 212300 & 154100 \\
$\mathrm{n}$ at maximum shear rate $(\mathrm{cp})$ & 3264 & 3381 & 2085 \\
Farrow's constant & 5.4 & 4.74 & 4.15 \\
Zone of inhibition $(\mathrm{mm})$ & $23.9 \pm 0.1$ & $21.9 \pm 0.06$ & $43.0 \pm 0.2$ \\
(mean $\pm \mathrm{SD}, \mathrm{n}=3)$ & None & None & None \\
Skin irritation & & $\mathrm{F} 1)$, thyme oil alone (F7), and thyme oil + lemon grass oil
\end{tabular}


moderate activity and the least activity was exerted by rosemary oil. Thyme and lemon grass oils were selected for further investigation because of their inhibitory activities against MRSA as well as for their high yield.

Antibacterial activity has been attributed to the presence of some constituents in the oils. Citral, geranyl acetate, $\beta$-pinene and $\beta$-myrcene were the major components in lemon grass oil, while $\gamma$-terpinene, thymol, $\beta$-caryophyllene and $\delta$ cadinene constituted the major components of thyme oil. Researchers reported lemon grass oil contents of citral and $\beta$-myrcene similar to that obtained in present study, but different from those reported for exotic lemon grass oil [15]. This variation could be explained due to the different stages at which the lemon grass was harvested. On the other hand, thymol was reported to be a major component of thyme oil [16], similar to what we observed in our study. It should, however, be noted that the yield and composition of essential oil can be markedly affected by geographical environment, soil properties, plant age and parts, seed source and method of isolation [17].

Citral is the major component of lemongrass oil is a natural mixture of two isomeric acyclic monoterpene aldehydes and is mainly responsible for the inhibitory activity against MRSA exerted by lemongrass oil [18]. On the other hand, thymol was one of the predominant active compounds found in thyme oil. Earlier studies suggest that the antibacterial activity of thyme oil against MRSA is probably due to thymol [19].

Ultimate acceptability and efficacy of such preparations require them to possess optimal physicochemical properties, viz, ease of removal from the container, spreadability on substrate, rheological properties and other properties such as antibacterial activity against MRSA. All the gels showed $\mathrm{pH}$ values in the normal $\mathrm{pH}$ range of the skin and were non-irritant, except for gels containing $\mathrm{Na} \mathrm{CMC}$. The therapeutic efficacy of a topical gel formulation also depends upon its spreadability. Hence, determination of spreadability is important in evaluating topical application characteristics [20]. The spreadability of the gels was optimum for all formulations. One of the most important properties of a mucoadhesive polymer is the viscosity of the aqueous solution. In agreement with Pena, the viscosities of the gels were found to be directly proportional to polymer concentration [21].

Knowledge of the viscosities could provide some insight about their expected mucoadhesive strength [22].Gel viscosity was determined at minimum and maximum shear rates. Minimum rate of shear is used to reflect viscosity at rest, e.g., on shelf while viscosity at maximum shear rate reflects viscosity during the manufacturing process [23].

The gel containing $0.75 \%$ carbopol 940 (F1) showed appropriate viscosity at minimum and maximum rates of shear.

\section{CONCLUSION}

The physicochemical properties of the gels containing $0.75 \%$ carbopol 940 together with lemon grass oil or thyme oil alone, or a mixture of both were the most appropriate for topical application. The activities of the lemon grass oil and thyme oil was not significantly affected by their incorporation in the gel. The gels showed promising antibacterial activity against MRSA. Carbopol $940(0.75 \%) \mathrm{gel}$ is a promising vehicle for the topical administration of the two essential oils.

\section{REFERENCES}

1. Lawrence JC. Dressings and wound infection. Am J Surg 1994; 167 (suppl 1A): 21S-24S.

2. Naimi TS, LeDell KH, Boxrud DJ, Groom AV, Steward CD, Johnson SK, Besser JM, Boyle CO, Danila RN, Cheek JE, Osterholm MT, Moore KA, Smith KE. Epidemiology and clonality of community-acquired methicillinresistant Staphylococcus aureus in Minnesota (1996-1998). Clin. Infect. Dis. 2001; 33: 990-996.

3. Grundmann H, Aires-de-Sousa M, John BJ, Tiemersma E. Emergence and resurgence of meticillin-resistant Staphylococcus aureus as a public-health threat. Lancet 2006; 368: 874-885.

4. Sue C, Gary Y, Craig O, Karen N. Inhibition of methicillin-resistant Staphylococcus aureus (MRSA) by essential oils. Flavour Fragr. J. 2008; 23: 444-449.

5. USP 34: United States Pharmacopeia and the National Formulary (USP 34 - NF 29). Rockville (MD): The United States Pharmacopeial Convention; 2011.

6. Adams RP. Identification of Essential Oil Components by Gas Chromatography/Mass Spectroscopy. Allured Publishing Corporation, Carol Stream, Illinois, $4^{\text {th }}$ ed. USA; 2001.

7. Charnock C, Brudeli B, Klaveness J. Evaluation of the antibacterial efficacy of diesters of azelaic acid. Eur J Pharm Sci. 2004 Apr ; 21(5): 589-96.

8. Lucero M J, Vigo J, Leon MJ. A study of shear and compression deformations on hyrogels of tretinoin. Int. J. Pharm. 1994; 106: 125.

9. Jain S, Padsalg BD, Patel AK, Mokale V. Formulation, development and evaluation of Fluconazole gel in various polymer bases. Asian J Pharm. 2007; 1: 63-8

10. Chakole CM, Shende MA, Khadatkar SN. Formulation and development of novel combined halobetasol propionate and fusidic acid ointment. Int $\mathrm{J}$ Chem Tech Res. 2009; 1: 103-16.

11. Ibrahim HK. A Novel Liquid Effervescent Floating Delivery System for Sustained Drug Delivery. Drug Discov. Ther. 2009; 3: 168-175. 
12. Drews WL, Barry AL, O Toole R, Sherris JC. Reliability of the Kirby-Bauer disc diffusion method for detecting Methicillin-resistant strains of Staphylococcus aureus. PPL Microbiol. 1972; 24: 240-247.

13. Shivhare UD, Jain KB, Mathur VB, Bhusari KP, Roy AA. Formulation development and evaluation of diclofenacsodium gel using water soluble polyacrylamide polymer. Digest J. Nanomat. Biostruct. 2009; 4: 285-290.

14. Friedman M, Henika PR, Mandrell RE. Bactericidal Activities of Plant Essential Oils and Some of Their Isolated Constituents against Campylobacter jejuni, Escherichia coli, Listeria monocytogenes, and Salmonella enterica. J. Food Prot 2002: 65: 1545-1560.

15. Loumouamou AN, Biassala E, Silou TH, Ntondele N P, Diamouangana J, Nzikou JM, Chalchat JC, Figuérédo G. Characterisation of a Giant Lemon Grass Acclimatised in the Congo-Brazzaville. Adv. J. Food Sci. Technol. 2010; 2 (6): 312-317.

16. Alexandre P, Ronoel LOG. Chemical Composition of Thymus vulgaris $L$. (thyme) essential oil from the Rio de Janeiro (Brazil). J . Serb . Chem . Soc. 2005; 73 (3): 307-310.

17. Sharafzadeh S, Alizadeh A, Sarvestani MMS. Comparison of Essential Oil yield and Components in Two Parts of Garden Thyme Shoot. Adv. Environ. Biol . 2011; 5 (10): 3179-3182.

18. Amna A. Saddiq, Suzan A. Khayyat. Chemical and antimicrobial studies of monoterpene: Citral. Pestic Biochem. Physiol. 2010; (98): 89-93.

19. Gallucci N, Oliva M, Carezzano E, Zygadlo J, Demo M. Terpenes antimicrobial activity against slime producing and non-producing staphylococci. Mole Med Chem. 2010; (21): 132-136.

20. Lakshmana PS, Shirwaikar A, Shirwaikar A, Kumar A. Evaluation of rosin as a cream base for topical ketoconazole preparation. Pharm Res. 2009; 8 (2): 89-92.

21. Pena $L E, G e l$ dosage forms: theory, formulation and processing; in: Osborne DW, A mann $A H(E d)$. Topical drug delivery formulations, Marcel Dekker, New York, 1990; pp. 381- 388.

22. Hassan EE, Gallo JM. A simple rheological method for invitro assessment of mucin- polymer bioadhesive bond strength ; Pharm. Res. 1990; 7: pp. 491-495.

23. Martin A, Bustamanta $P$, Chun A HC. Physical Pharmacy; $4^{\text {th }}$ ed., Lea and Febiger, Philadelphia. 1993; pp 453-465. 